\title{
DESIGN OF DC CHOPPER CONTROL CIRCUIT
}

\author{
Ali H. A. Al-Obaidly ${ }^{1}$ - \\ ${ }^{1}$ B.Sc. Electrical Engineer Electrical Power Department, Public Authority for Applied Education and Training(PAAET), \\ Kuwait
}

Received 6 May 2021

Accepted 20 May 2021

Published 31 May 2021

Corresponding Author

Ali H. A. Al-Obaidly, alialobaidly74

@gmail.com

DOI $10.29121 /$

ijetmr.v8.i5.2021.954

Funding: This research received no specific grant from any funding agency in the public, commercial, or not-for-profit sectors.

Copyright: (C) 2021 The Author(s). This is an open access article distributed under the terms of the Creative Commons Attribution License, which permits unrestricted use, distribution, and reproduction in any medium, provided the original author and source are credited.

\section{ABSTRACT}

The aim of this research is to design a control power circuit which has the ability to operate the solenoid valve, the pump and the DC motor of the bottle filling machine. This circuit contains of three main parts the PIC16F876a, the Interface Circuit and the Snabber Circuit. The power circuit is supplied by $110 \mathrm{~V}$. The microcontroller (PIC 16F876a) is supplied by $5 \mathrm{~V}$. The power switch MOSFET is supplied by $24 \mathrm{~V}$. The Snabber Circuit and the interface circuit are designed in this research. The purpose and the role of the Snabber circuit and the Interface Circuit in the power control circuit are determined in this research.

Keywords: Dc Motor, Power Circuit, Control Circuit, Snabber Circuit, Interface Circuit

\section{INTRODUCTION}

The control of electric power with power electronic devices has become increasingly important over the last 20 years. Whole new classes of motors have been enabling by power electronics, and the future offers the possibility of more effective control of the electric power grid using power electronics. The modern of power electronics began with the introduction of thyristors in the late 1950s. Now there are several types of power devices available for high-power and high-frequency application. The most notable power devices are gate turn-off thyristors, power Darlington transistors, power MOSFETs, and insulated-gate bipolar transistors (IGBTs). Power semiconductor devices are the most important functional elements in all power conversion applications. The power devices are mainly used as switches to convert power from one form to another. They are used in motor control systems, uninterrupted power supplies, high-voltage DC transmission, power supplies, induction heating, and in many other power conversion applications Enkat (2001); Skvarenina (2002).

Figure 1 illustrates the block diagram of the control circuit using microcontroller of DC motor. For controlling the DC motor using microcontroller, many circuits must 
be designed for this purpose. The first circuit is the load circuit. The circuit contains the motor under control and the power switch used for the control. The power switch used is the power MOSFET. The power MOSFET must be protect against over voltage as well as over current. the MOSFET is controlled from its gate. The gate is controlled using a train of pulses generate with specific amplitude and frequency for specific application. The MOSFET gate is triggered by the pulses out from interface circuit design for specific application. The interface circuit are designed from several stages of normally off transistor circuit. The main aim of the previous circuit is the amplification. The triggering pulses are generated from the microcontroller 16f876a according to specific operation strategy programmed within it. The last circuit is the microcontroller circuit. This circuit contains the microcontroller itself, its biasing circuit from 5V DC supply. The input to the microcontroller is an analog input used for triggering it. The output of the PIC is a pulse width modulation output. This output depends upon the operation strategy programmed for the control purpose of the load connected to the motor under control.

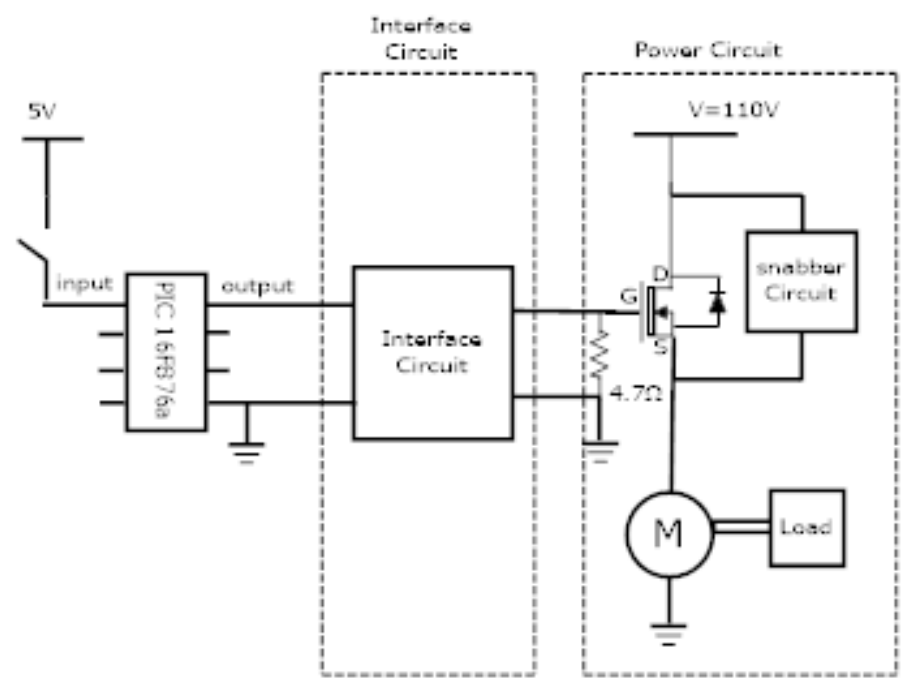

Figure 1 Block Diagram of the ControlCircuit Using Microcontroller of DC Motor.

The purpose of a DC - DC converters is to supply a regulated DC output voltage to a variable -load resistance from a fluctuating DC voltage. In many cases the DC input voltage is obtained by rectifying a line voltage that is changing in magnitude. DC DC converters are commonly used in application requiring regulated DC power, such as computer, medical instrumentation, communication devices, television receivers, and battery chargers P (2001), Mohan and Robbins (1995). DC-DC converters are also used to provide a regulated variable DC voltage for DC motor speed control application. The output voltage in DC-DC converters is generally controlled using a switching concept, as illustrated by the basic DC-DC converter. Early DC-DC converters were known as choppers with silicon-controlled rectifiers (SCRs) used as the 
switching mechanisms. Modern DC-DC converters classified as switch mode power supplies (SMPS) employ insulated gate bipolar transistors (IGBTs) and metal oxide silicon field effect transistors (MOSFETs).

The switch mode power supply has several functions Enkat (2001):

1. Step down an unregulated DC input voltage to produce a regulated DC output voltage using a buck or step -down converter.

2. Step up an unregulated DC input voltage to produce a regulated DC output voltage using a boost or step-up converter.

3. Step down and then step up an unregulated DC input voltage to produce a regulated DC output voltage using a buck-boost converter.

4. Invert the DC input voltage using a Cuk converter.

5. Produce multiple DC output using a combination of SMPS topologies.

The most notable power devices are gate turn-off thyristors, power Darlington transistors, power MOSFETs, and insulated-gate bipolar transistors (IGBTs). Power semiconductor devices are the most important functional elements in all power conversion applications. The power devices are mainly used as switches to convert power from one form to another. They are used in motor control systems, uninterrupted power supplies, high-voltage DC transmission, power supplies, induction heating, and in many other power conversion applications P (2001), Enkat (2001). There are two ways to control with DC motor; mechanical and electrical, one of the electrical ways is DC CHOPPER. A chopper circuit is used to refer to numerous types of electronic switching devices and circuits. Through this paper, Different levels of voltages are supplied to the load using the Chopper. The illustration of the effect of voltage levels to the load is illustrated. The effect of frequency levels upon the performance of the Chopper circuit is presented. The DC Chopper output current is analyzed at different duty cycles is illustrated. The effect of changing frequency is presented through the paper. Chopper drives are used all over the world in traction applications such as battery electric vehicles and mass rapid transit systems. A DC chopper is connected between a fixed-voltage DC source and a DC motor to vary the magnitude of the armature voltage. In addition to armature voltage control, a DC chopper can provide regenerative braking of the motors and can return energy back to the supply Moghbelli et al. (1993). The chopper system can offer several operational benefits over conventional means of rectification Urban (1998).

\section{MATERIALS AND METHODS}

\subsection{DESIGN OF THE DC MOTOR CONTROL CIRCUITS USING MICROCONTROLLER}

The design of the control circuits is initiated by the load circuit and terminated by the PIC circuits. 


\subsubsection{LOAD CIRCUIT}

The load circuit contains the following;

- Power supply: which is $220 \mathrm{~V}$ AC supply, Bridge circuit to rectify the AC voltage to the required voltage used for the motor which is $110 \mathrm{~V}$ DC.

- DC Motor: The DC motor under control has datasheet parameters of 180V DC and $6 \mathrm{amp}$. The motor is operated at 110V. the motor load is a mechanical system used for filling automatically several bottles by a dangerous liquid.

- Power switch: The power used for controlling the load system is a power MOSFET. The operation region of the MOSFET depends upon the load connected to the motor which is approximately $6 \mathrm{~A}, 110 \mathrm{~V}$.

- Snabber circuit: The snabber circuit used for protecting the MOSFET against $\mathrm{dv} / \mathrm{dt}$. This circuit contains diode, capacitor and resistor.

\subsubsection{CIRCUIT DIAGRAM OF THE POWER CIRCUIT}

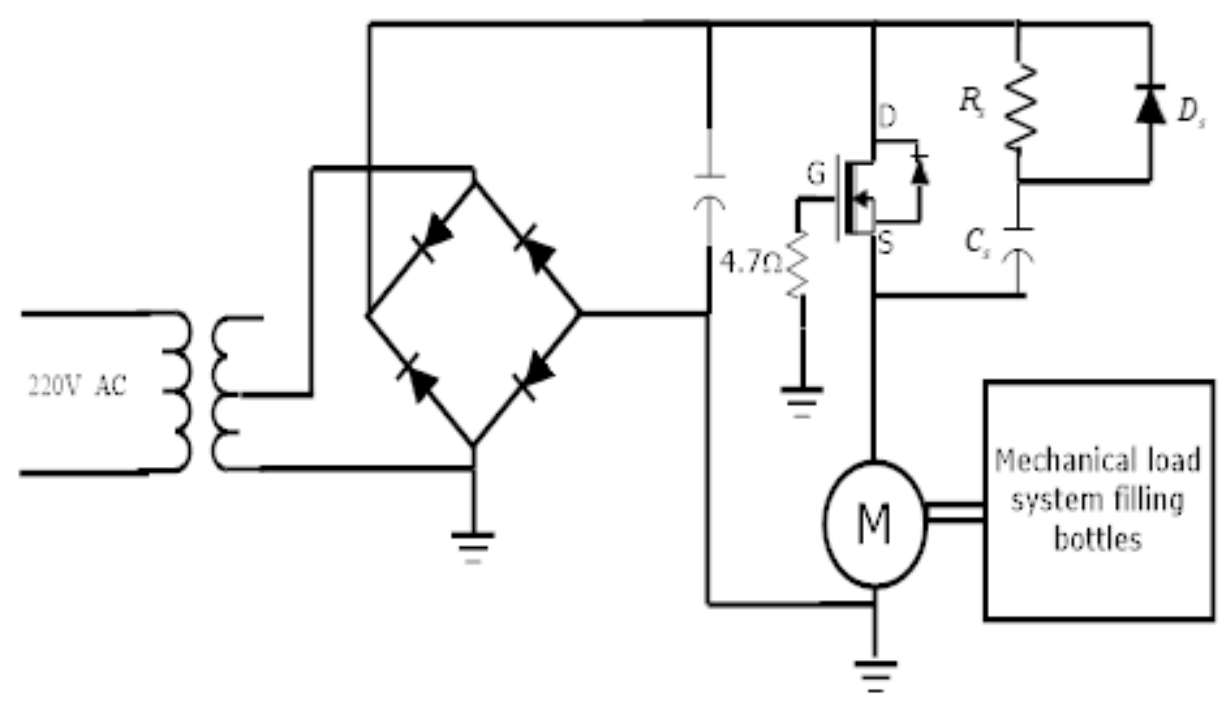

Figure 2 Power Circuit of theControlling System of DC Motor Using Microcontroller.

Figure 2 illustrates the power circuit of the controlling system of DC motor using microcontroller.

\subsubsection{DESIGN OF SNABBER CIRCUIT}

Figure 3 illustrates the Snabber circuit using for protection the power MOSFET used to control the DC motor. the application of a fast-rising forward voltage across an MOSFET under off state conditions results in the flow of current across the junction 


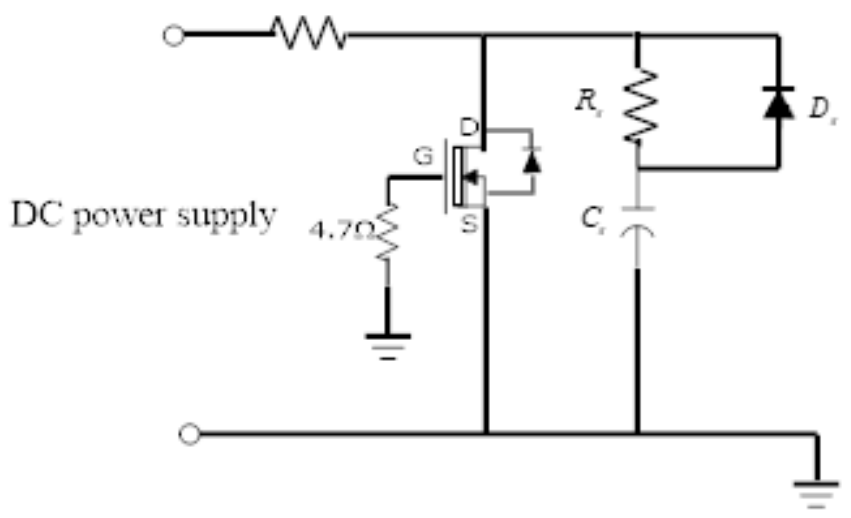

Figure 3 CircuitDiagram of the Snabber Circuit.

into the gate layer. The current will turn the MOSFET on if it exceeds the critical value. The RC Snabber circuit is used to prevent unscheduled firing in circuits with high values of dv/dt. A small capacitance across the MOSFET reduces the rate at which the voltage across the MOSFET can change. An approximate value for the capacitance $C$ can be obtained by finding the time constant $\mathrm{T}$ and load Rs

$$
\begin{aligned}
& \frac{V_{D R M}}{T}=\frac{d v}{d t_{\max }} \\
& \text { and } T \leq R C \\
& C \geq \frac{T}{R_{x}} \geq \frac{V_{D R M}}{R_{x} d V / d t_{\max }} \\
& \text { and } T \geq t_{\text {off }}
\end{aligned}
$$

ton is the MOSFET on time

When the MOSFET is off, the capacitor charges up in a positive direction up to the instant that MOSFET turn on. When the MOSFET is triggered on, the capacitor discharges and adds to the di/dt presented by the original circuit. Therefore, a small resistor Rs is added in series with the capacitor to slow the capacitor discharge and limit the current transient at turn-on. An approximate value of Rs is obtained as;

$$
R_{x} \geq \sqrt{\frac{V_{\text {DQV }}}{(d i / d t)_{\max }}}
$$

A suitable value would be $100 \Omega$.(di/dt) max is the rate of change of current rating of the MOSFET in $\mathrm{A} / \mu$ s.

Although the addition of Rs protects the MOSFET from high values of di/dt, it lowers the dv/dt capability of the MOSFET. To extend dv/dt, a small diode Ds is connected 
across Rs.

The design of snabber circuit means the determination of Rs and Cs. The values of these parameters depend on the data sheet parameters of the power switch MOSFET. Hence, from datasheet parameters of the MOSFET used, the di/dt, dv/dt and its breakover voltage must be determined. The values of the previous parameters are obtained from the datasheet of the used MOSFET which are as follows;

$$
\begin{aligned}
& \text { ton }=\mathrm{tr}+\text { ton }=50+80=130 \mathrm{~ns} \\
& \text { toff }=200 \mathrm{~ns} \\
& \text { maximum drain source voltage }=900 \mathrm{~V} \\
& \text { maximum Gate source voltage }= \pm 30 \mathrm{~V} \\
& \text { threshold voltage }=15 \mathrm{~V} \\
& \text { DC Drain current }=9 \mathrm{~A} \\
& \text { drain pulse current }=27 \mathrm{~A} \\
& \text { drain source } \mathrm{ON} \text { resistance }=1.4 \Omega
\end{aligned}
$$

consequently, the breakover voltage of the MOSFET used for the design is exceed; $V_{D R M} 900 \mathrm{~V}$. The rate of rising of the voltage upon the drain source of the MOSFET must not exceed;

$$
\left.\frac{d v}{d t}\right|_{\max } \leq \frac{900}{t_{o f f}}=\frac{900}{2 * 200 \mathrm{~ns}}=2.25 \mathrm{~V} / \mathrm{ns}
$$

Hence, as the voltage used upon the drain source is $110 \mathrm{~V}$, the time required for rising this voltage must become $\geq 48.8 \mathrm{~ns}$. So, the snabber circuit used for protecting the power switch MOSFET must has a time constant equal to or larger than $\geq 48.8$ ns, so that Rs Cs $\geq 48.8$ ns. The value of Rs is determined as

$$
\begin{aligned}
& R_{x} \geq \sqrt{\frac{V_{\text {DQM }}}{(d i / d t)_{\max }}} \\
& R_{x}=\sqrt{\frac{900}{\left(27 / t_{\text {aff }}\right)_{\max }}} \\
& R_{x}=\sqrt{\frac{900}{\left(27 / 200 * 10^{-9}\right)}} \\
& R_{x}=2.5 \mathrm{~m} \Omega
\end{aligned}
$$

As the current passes through the MOSFET is DC, the value of (di/dt) max must has the following value; 


$$
\begin{aligned}
& R_{x} \geq \sqrt{\frac{V_{\text {DQY }}}{(d i / d t)_{\max }}} \\
& R_{x}=\sqrt{\frac{900}{\left(9 / t_{\text {off }}\right)_{\max }}} \\
& R_{x}=\sqrt{\frac{900}{\left(9 / 200 * 10^{-7}\right)}} \\
& R_{x}=4.4 \mathrm{~m} \Omega
\end{aligned}
$$

So, the selection of $R s$ must be in the range of

$2.5 \mathrm{~m} \Omega \leq R s \leq 4.4 \mathrm{~m} \Omega$.

So, select $R s=3 \mathrm{~m} \Omega$

Hence,

$$
\begin{aligned}
& C_{x} \geq \frac{48.8 n s}{R_{x}} \\
& C_{x} \geq \frac{48.8 * 10^{-9}}{3 * 10^{-3}} \\
& C_{x}=16.26 \mu F
\end{aligned}
$$

The last element in the snabber circuit must be designed is diode Ds. The diode selection depends upon the reverse voltage as well as the current passes through it. The reverse voltage of the diode is $110 \mathrm{~V}$, and the current through it is $(110 / 1.4)=78.5$ A.

\subsubsection{DESIGN OF THE INTERFACE CIRCUIT}

The purpose of the interface circuit (Figure 4 ) is to connect the microcontroller output to the gate to source current of the MOSFET power switch. The maximum PIN input or output current of the PIC pins is $25 \mathrm{~mA}$ as shown from microcontroller datasheet. The interface circuits are the stages of normally off transistor circuits. In this research the transistor used for designing the interface circuit is 2 N3904. This transistor has the following specification;

as the transistor operates such that the collector emitter saturation voltage becomes $0.2 \mathrm{~V}$. The required base current will be $1 \mathrm{~mA}$ and the collector current Ic is $10 \mathrm{~mA}$ as shown from datasheet. Consequently, the interface circuit is a normally off transistor circuit as shown in the following (Figure 5 ). When the transistor is in the $\mathrm{ON}$ condition, $\mathrm{VBEON}$ is $0.85 \mathrm{~V}$. Hence,

$$
\begin{aligned}
& R_{B}=\frac{5-0.85}{1 \mathrm{~mA}}=4.15 \mathrm{~K} \Omega \\
& R_{C}=\frac{24-0.2}{10 \mathrm{~mA}}=2.38 \mathrm{~K} \Omega
\end{aligned}
$$




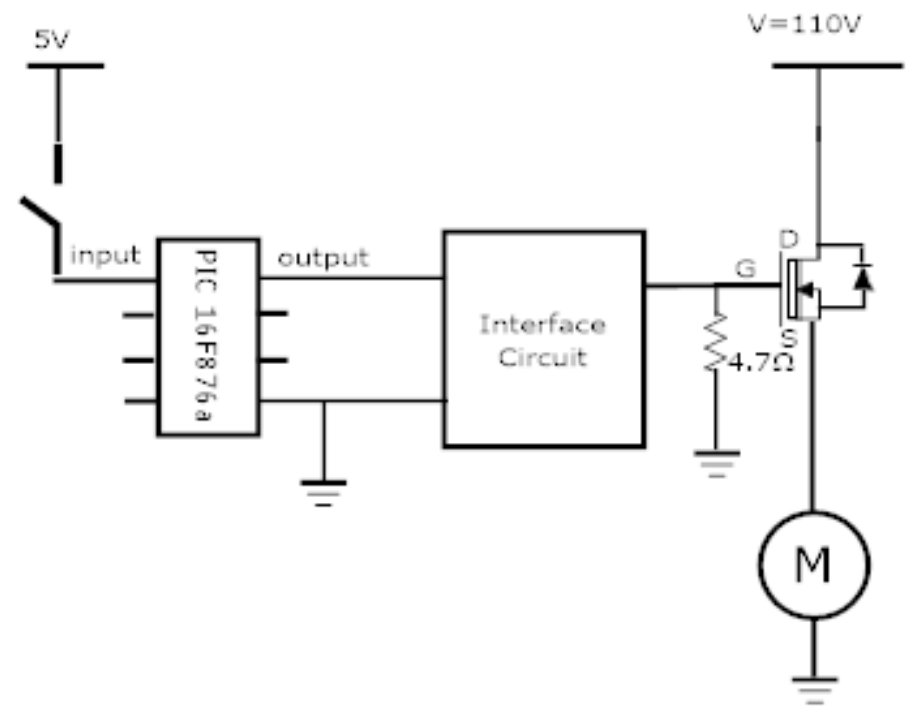

Figure 4 Block Diagram of InterfaceCircuit.

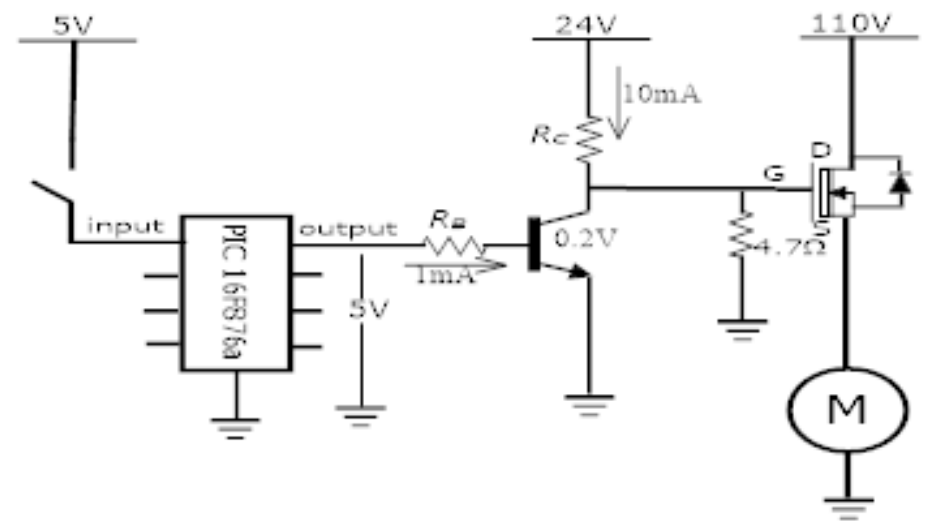

Figure 5 Interface Circuit.

\section{RESULTS AND DISCUSSIONS}

Rc \& RB are designed in the interface circuit. The interface circuit is supplied by 24 V. Cs, Rs and Ds are designed in the Snabber circuit. The Snabber circuit is supplied by $110 \mathrm{~V}$. Figure 6 illustrate the power and control circuit designed to operate three elements of the filling bottle machine. The three elements are the Pump, the Motor and the Solenoid Valve. The operating of the Pump, the Motor and the Solenoid Valve depend on the microcontroller. The output voltage of the microcontroller is $5 \mathrm{~V}$. The filling bottles machine system is managed by microcontroller. The Motor, the Pump 
and the Solenoid Valve, All of them has an interface circuit and a MOSFET. The microcontroller output operates the interface circuit, consequently, the interface circuit turns on the MOSFET gate. By programming the microcontroller, the Pump circuit turns on to fill the tank with liquid, then the Motor circuit turns on to put the bottle exactly under the Solenoid Valve, after that, the Solenoid Valve circuit turns on to fill the bottle with liquid. This cycle is repeated until the bottles is finished.

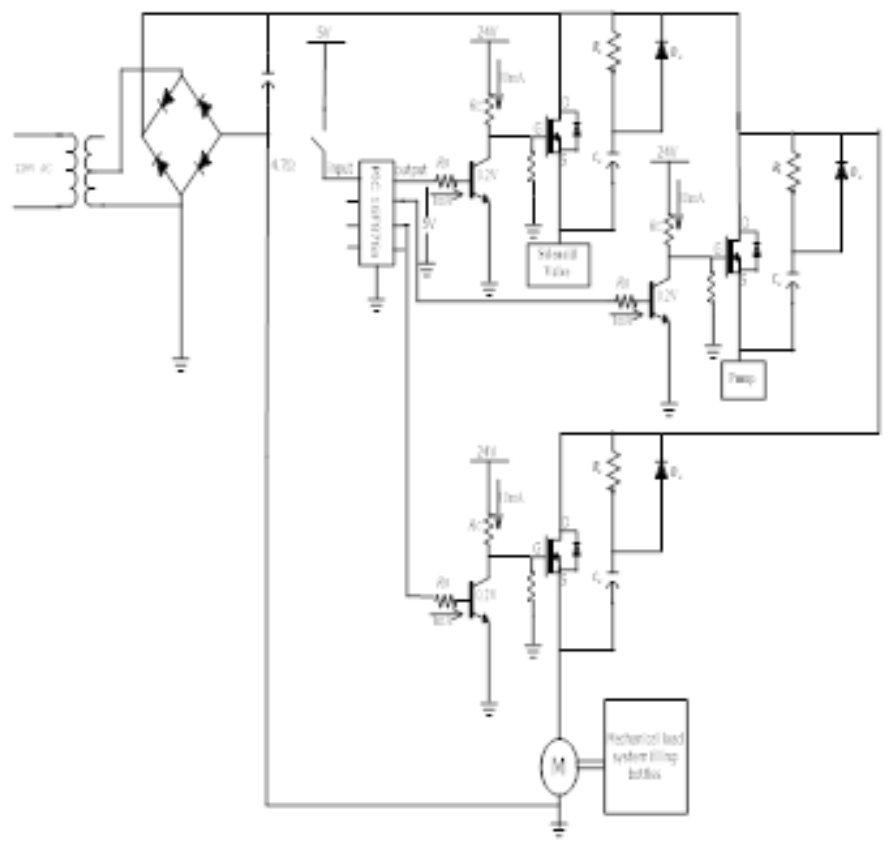

Figure 6 Power and control Circuits.

\section{CONCLUSIONS AND RECOMMENDATIONS}

In this research, the power and control circuit are designed for controlling the Mechanical load system filling bottles by using the microcontroller (PIC 16F876a). The Pump, the Motor and the Solenoid Valve are controlled by the microcontroller outputs. The Snabber circuit is designed to protect the power MOSFET. The interface circuit is designed to connect the microcontroller output to the gate of the MOSFET power switch. Writing a computer program and downloading it on a (PIC 16f876a) to control the Pump, the Motor and the Solenoid Valve is recommended. Illustrating the waves of the Pump, the Motor and the Solenoid Valve on the oscilloscope is recommended. 


\section{ACKNOWLEDGEMENTS}

I would like to express my deepest appreciation to the Public Authority for Applied Education and Training (PAAET) for helping me in this paper research.

\section{REFERENCES}

Enkat, R. (2001). Switch Mode Power Supply. In Switch Mode Power Supply. Sydney, Australia. Moghbelli, H., , \& Hanas, G. (1993). Chopper Design For Nictd Locomotives. Railroad Conference, 1993., Proceedings of The 1993 Ieee/Asme Joint, 67-75.

Mohan, N. U., \& Robbins, T. M. (1995). In Power Electronics. Power Electronics: Converters, Application, And Design.

P, J. (2001). Power Electronics. Power Electronics: Theory And Design Ed Prentice-Hall, Upper Saddle River , Nj.

Skvarenina, T. L. (2002). The Power Electronics Hand Book. The Power Electronics Hand Book. Urban, V. S. A. B. M. (1998). High Current Dc Choppers And Their Operational Benefits. Presented At The Conf. Rec. Ieee/Iaspcic. 